\title{
Multisystem vascular disease with successful multisystem percutaneous transcatheter revascularization: Total body stenting
}

\begin{abstract}
Patients with diabetes mellitus along other risk factors are vulnerable to develop micro and macro vascular disease including coronary artery, carotid, upper and lower extremities peripheral vascular disease. Physicians dealing with patients with coronary artery disease should at least suspect a disease(s) within other vascular territory or system and vies a versa for this at risk patients. We report a case of 74 year old male patient with history of heavy smoking, chronic obstructive pulmonary disease (COPD), hypertension, diabetes, dyslipidemia, old stroke, chronic renal impairment and chronic anemia. He was referred from another hospital, with history of recurrent, transient ischemic attacks (TIAs), right upper limb and bilateral lower limb claudication, chest pain and three episodes of Non ST elevation Myocardial infarction within the last 2 months. Cardiac catheterization showed multivessel Coronary Artery Disease (CAD), severe occlusive peripheral arterial vascular disease (PAD), in addition to occluded right subclavian and critical bilateral internal carotid artery subtotal stenosis were found and managed successfully with multisystem Percutaneous Transcatheter intervention with near total body stenting.
\end{abstract}

Keywords: Diabetes mellitus - Multisystem vascular disease - Transcatheter Revascularization

\section{Introduction}

Having a vascular pathology in one site, raise the probability of having other sites affected by about $50 \%$ within the vascular axis $[1,2]$. Hence once vascular pathology found in one site for example CAD, other sites i.e. Cerebral and peripheral circulation must be assessed thoroughly, especially in patients with multiple risk factors i.e. Hypertension, Diabetes, Dyslipidemia, Smoking, and positive family history for CAD. Assessment should view symptoms via a meticulous history, detailed examinations to exclude signs of ischemia, and thorough investigations. This will lead to accurate diagnosis and hence adequate management.

\section{Case Presentation}

74 year old male patient with history of longstanding heavy smoking, COPD, hypertension, diabetes, dyslipidemia, chronic kidney impairment, chronic anemia, old stroke, symptomatic peripheral vascular disease including occluded right subclavian, bilateral superficial femoral arteries (SFA), right tibioperoneal (TPT) trunk, right external iliac, symptomatic bilateral critical internal carotid artery stenosis, multivessel CAD, Status post three recent episodes of Non ST elevation Myocardial infarction within 3 months prior to admission. The patient was referred from another hospital, for further investigation and managements i.e. for Coronary angiography and possible intervention at our center. On examination, patient was found to have S4 gallop, bilateral carotid bruit, feeble right upper limb circulation and pulses, monophasic bilateral anterior tibial, dorsalis pedis and posterior tibial Doppler signals. No residual neurological deficit.
Walid Hassan*, Ehab I Hasan, Mariam Hassan, Rehab Mohammed, Hussain Nassar, Shady Sahyoun

Department of Cardiovascular Disease, International Medical Center, Jeddah, Saudi Arabia

*Author for correspondence: Walid Hassan

Email: walidhassan275@gmail.com

Received date: September 10, 2019 Accepted date: September 17, 2019 Published date: September 24, 2019 


\section{Investigations}

ECG: sinus rhythm, $60 \mathrm{bpm}$, ischemic changes in the inferolateral leads.

Other labs: Hemoglobin $7.4 \mathrm{gm} / \mathrm{dl}$, createnin 1.32 umol/L, GFR 71.5, HbA1c 6.2\%, otherwise all labs including liver, cardiac enzymes and thyroid functions were within accepted limits.

Echocardiography: Left ventricle ejection fraction $55 \%$, Normal global Left ventricle wall motion, no significant valvular abnormality, Normal pulmonary arterial pressure (systolic pulmonary artery pressure of $21 \mathrm{mmHg}$ ), no pericardial effusion. Grade II diastolic dysfunction.

He underwent coronary angiogram, carotid angiogram, and peripheral angiogram, which showed severe multivessel CAD (severe left anterior descending artery
LAD 80\%-90\%, left circumflex LCX 80-90\% stenosis and right coronary artery chronic total occlusion RCA CTO), severe bilateral left and right internal carotid artery subtotal $95 \%$ to $99 \%$, and severe PVD with occluded right subclavian artery, occluded SFA bilaterally, right tibioperoneal (TPT) and significant right external iliac stenosis (Figures 1-12).

The patient was considered for coronary artery bypass surgery and decision was to treat his critical carotid artery stenosis first with stenting (deemed very high risk for carotid endarterectomy CEA) and his occluded right subclavian artery prior to Coronary Artery Bypass Graft $(\mathrm{CABG})$, and treat his peripheral bilateral superficial femoral arteries in the future sessions.

The patient has been evaluated by neurology team pre and post procedure, MRI brain showed left posterior

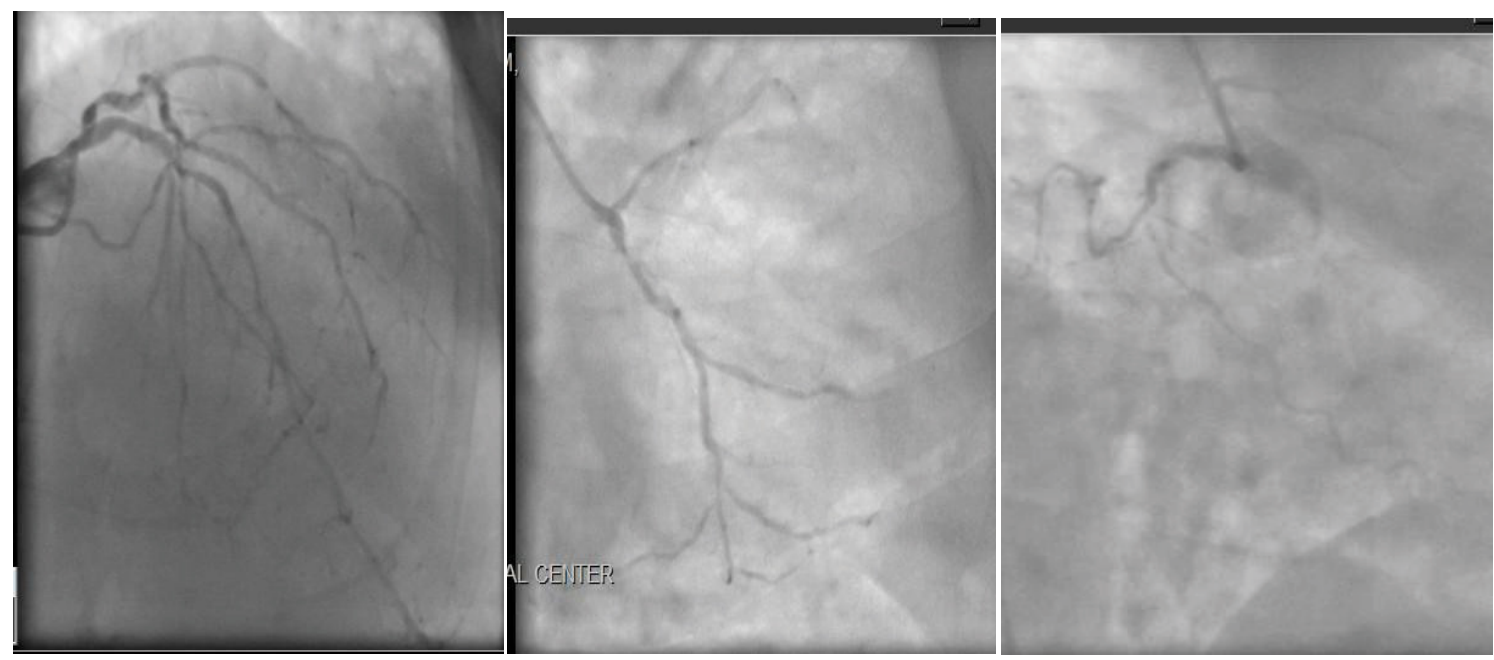

Figure 1: Coronary angiogram revealed severe LAD, LCX stenosis and RCA CTO.
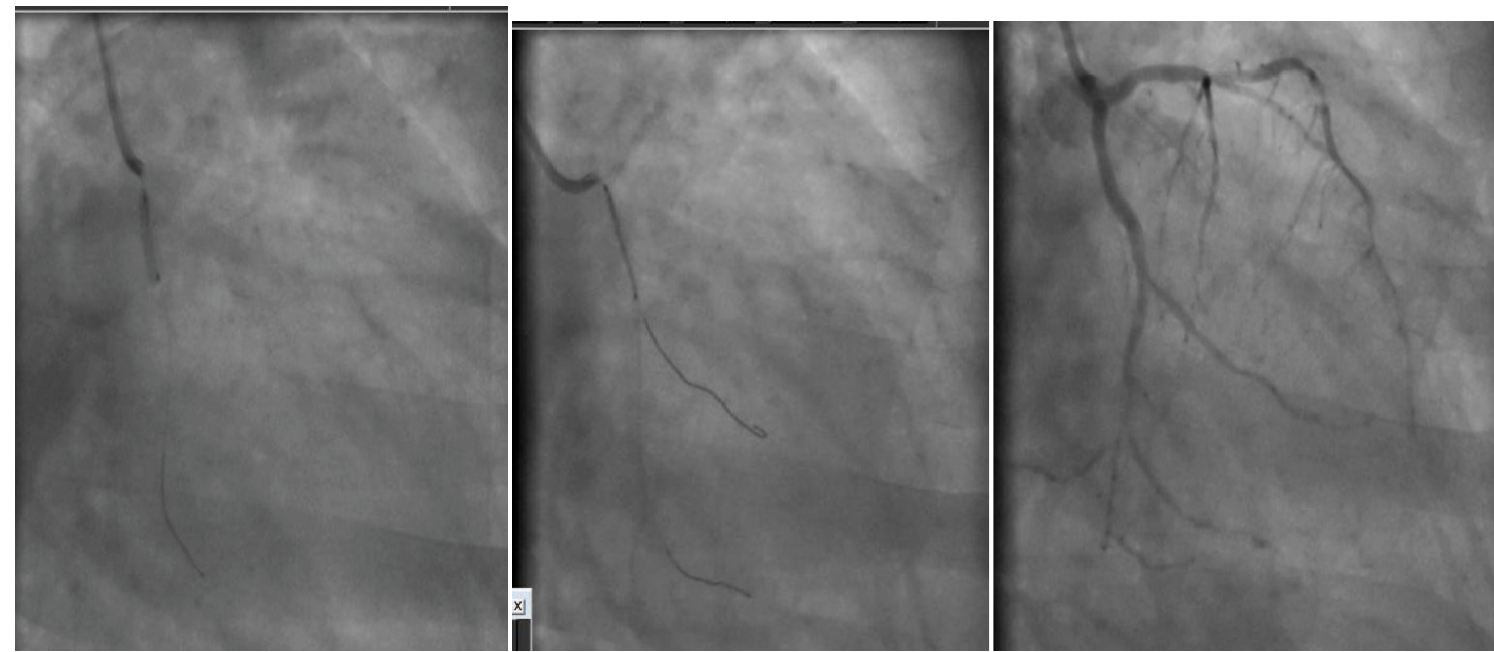

Figure 2: LCX Angioplasty and stenting. 

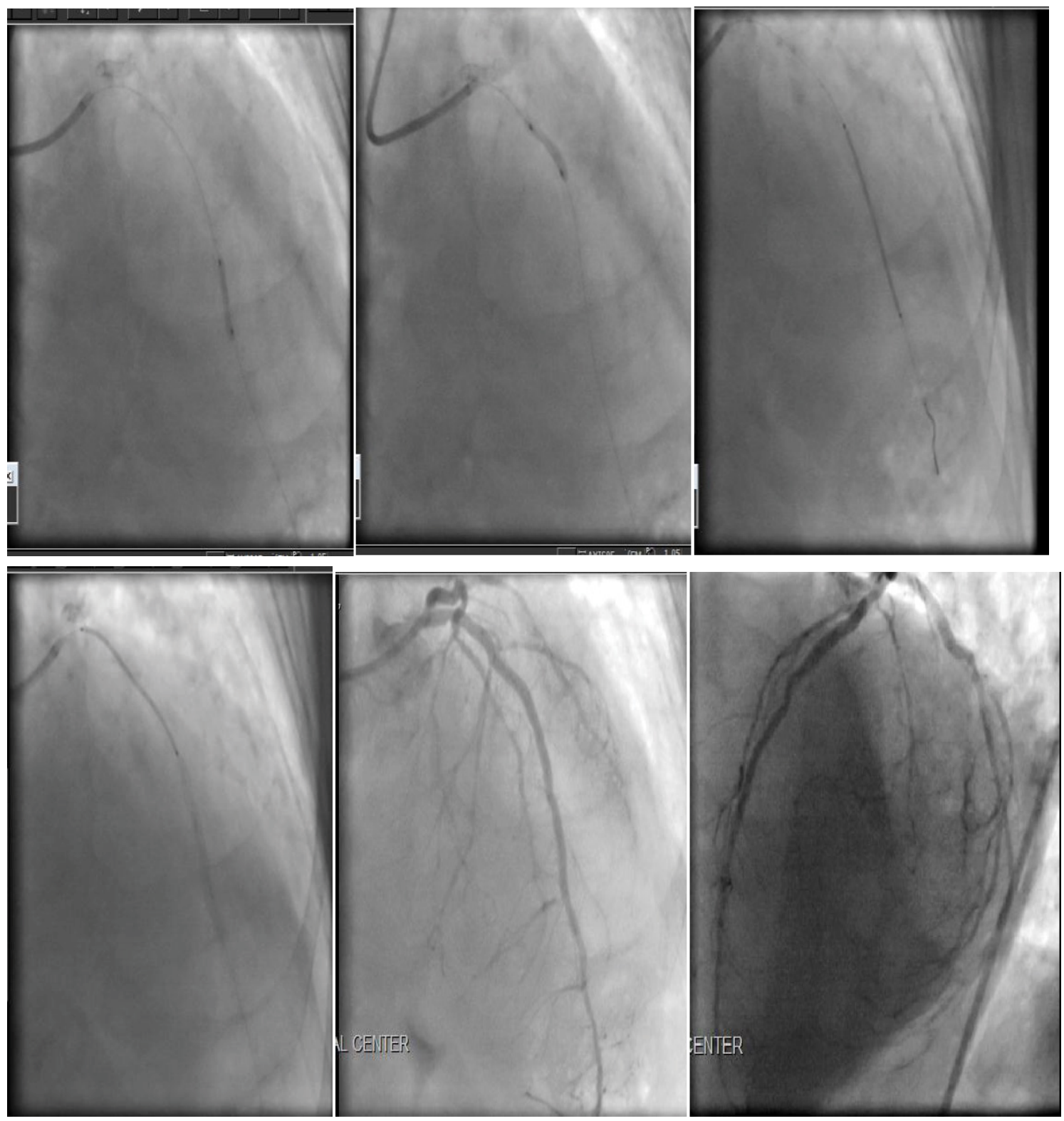

Figure 3: LAD Angioplasty and stenting.

and parietal old infarct with lacunar pontine old infarct but no acute insult or new neurological issues.

The patient underwent selective right carotid angiography, right cerebral angiography, and successful angioplasty and stenting to his subtotal occluded right internal carotid with self-expandable $8 \times 6 \times 30 \mathrm{~mm}$ XACT stent with NAV 6 Emboshield distal protection filter device after renal protection protocol (Figure 5). In the same setting we successfully treated his occluded right subclavian artery via both antegrade and retrograde approach using total occlusion wires, angioplasty balloon $(7 \times 40 \mathrm{~mm}$ Armada balloon) and stenting ( 8 $\times 60 \mathrm{~mm}$ self-expandable SMART Control stent) with excellent result with normalization of the right upper circulation and pulses (Figure 6). Then 3 days later the patient underwent selective left carotid angiogram and successful complex angioplasty and stenting to subtotal left internal carotid artery stenosis with another selfexpandable $9 \times 7 \times 39 \mathrm{~mm}$ XACT stent under distal protection with Emboshield NAV 6 filter device (Figure 7). There was no early or late complications, follow up post procedure MRI brain was repeated and showed no acute significant findings. Neurology team assessed the patient post procedure with no event or deficit.

Later the patient was not accepted for CABG (because of his severe co morbidities, old stroke and FEV1<1 liter) 
A

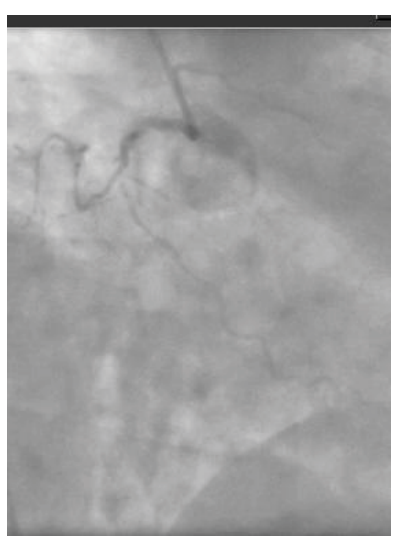

$\mathrm{E}$
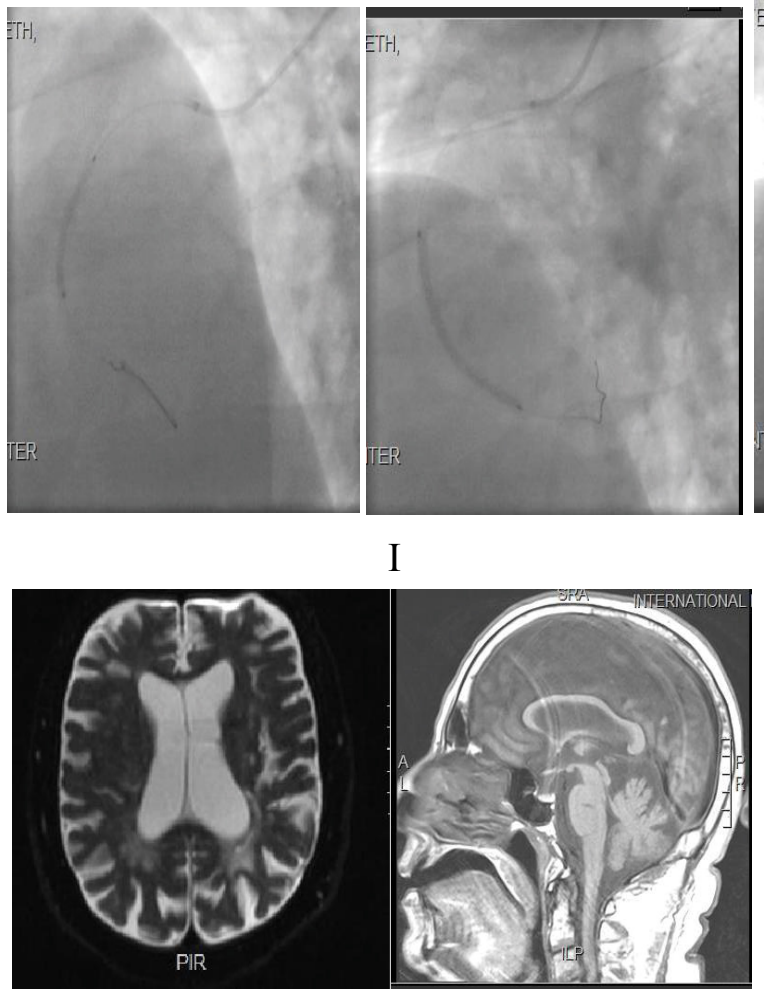

Figure 4: Angioplasty and stenting to RCA CTO (A) Occluded RCA (B) Wire crossing (C) Balloon angioplasty (D) Recanalization (E) Prox mid stent (F) Stent deployment (G and H) Post stenting wide patent RCA (I) MRI Pre (J) MRI Post.

with very high STS and EURO Score for preoperative mortality, and hence multivessel coronary stenting was planned as his best option and was continued on Aspirin, clopidogril, high dose statin, angiotensin converting enzyme inhibitor, beta blocker and nitroglycerine in addition to his non cardiac medications.

The following day the patient underwent elective multivessel coronary intervention, underwent successful complex angioplasty and drug eluting stents to LAD 2
$\mathrm{C}$

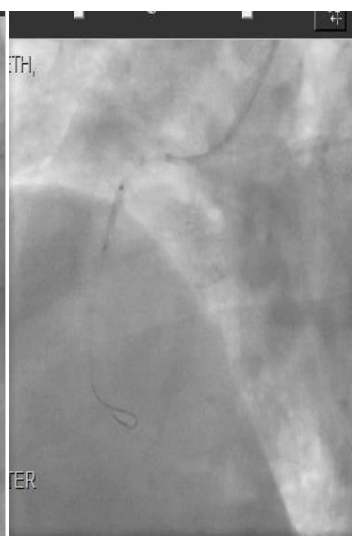

G

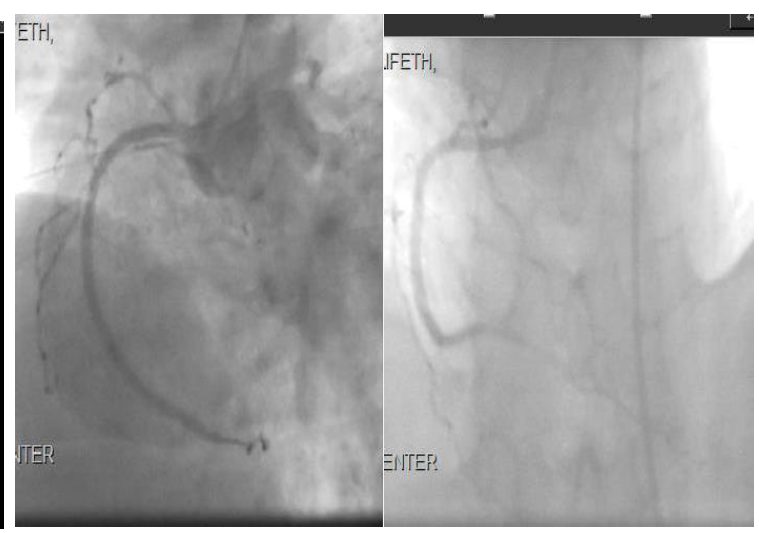

$\mathrm{J}$

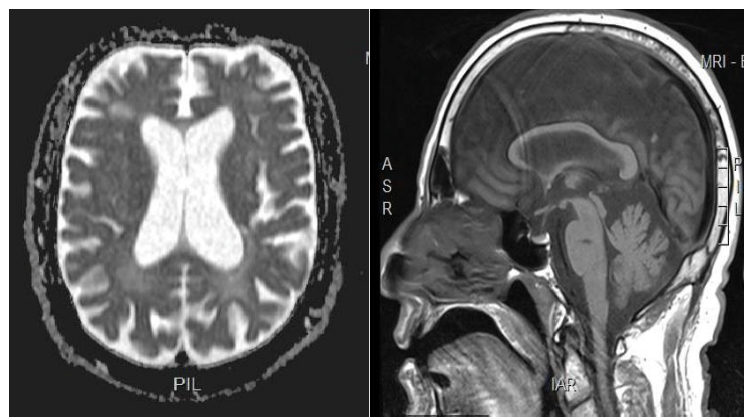

$\mathrm{D}$

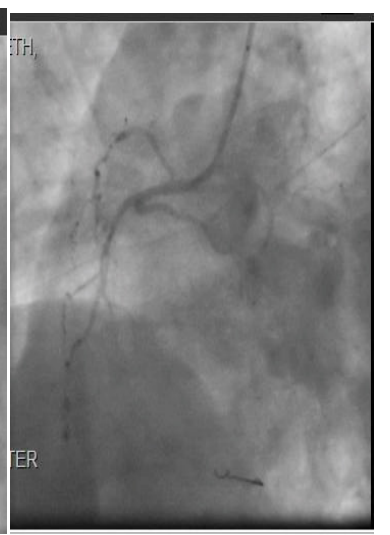

H 
A

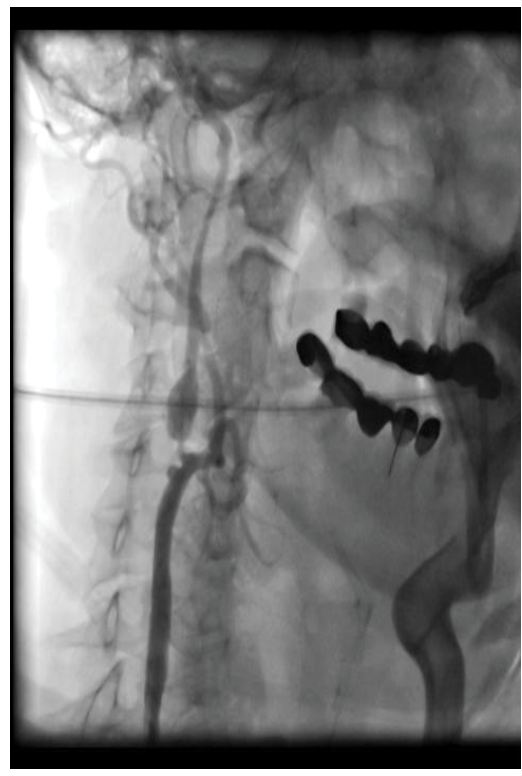

$\mathrm{D}$

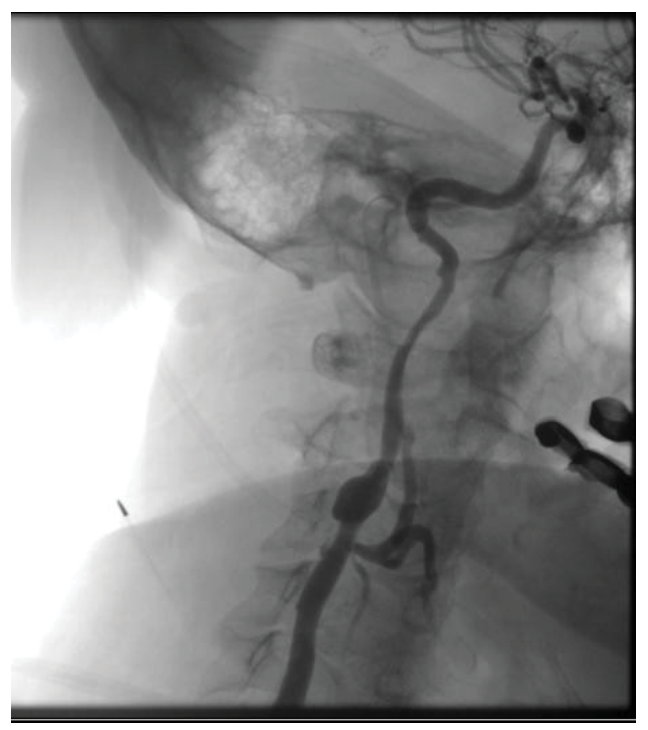

Figure 5: (A and B) Right internal carotid critical 99\% stenosis (C) Emboshield distal filter NAV6 and angioplasty (D) Post XACT stent $8 \times 6 \times 30 \mathrm{~mm}$.

successful complex angioplasty followed balloon expandable stent to his tight right external artery $(7 \times 59 \mathrm{~mm}$ Omnilink stent, Figure 8), and 3 self expandable peripheral stents to his occluded right SFA $(5 \times 150 \mathrm{~mm}, 6 \times 150 \mathrm{~mm}$ and $6 \times 60 \mathrm{~mm}$ Absolute Pro stents, Figures 9, 10) and coronary $4 \times 38 \mathrm{~mm}$ Promus Premier to his occluded right TPT (Figure 11) with excellent result and 3 vessels below knee distal run off. Then we proceeded with intervention to his
$\mathrm{C}$

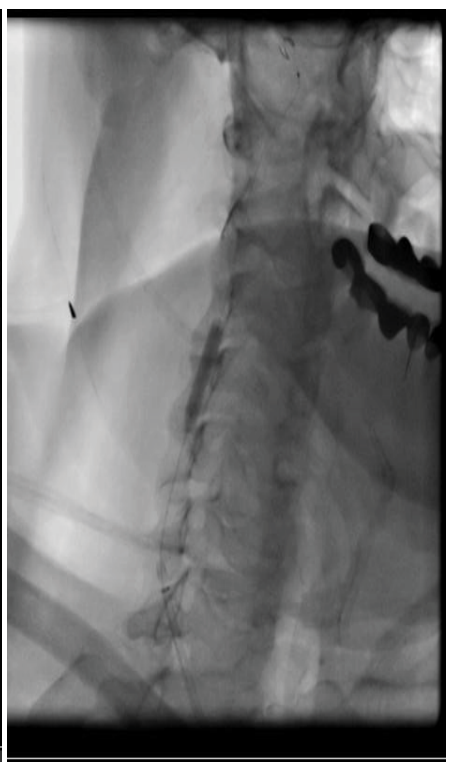

B

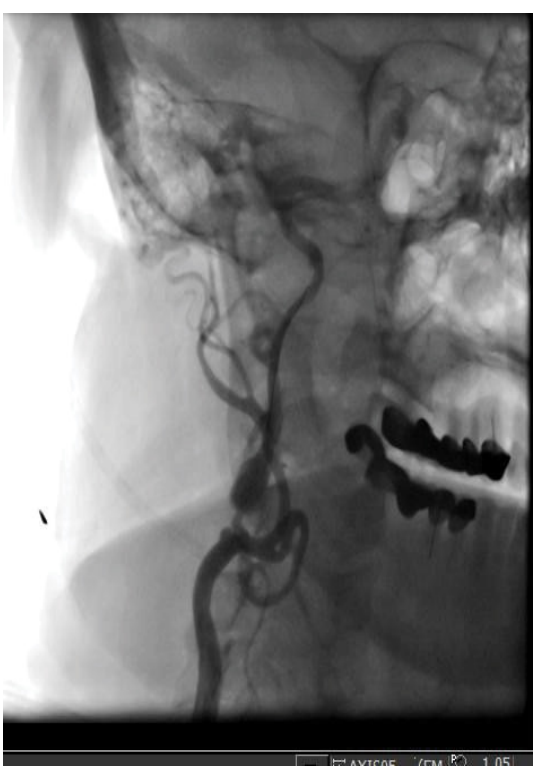


A

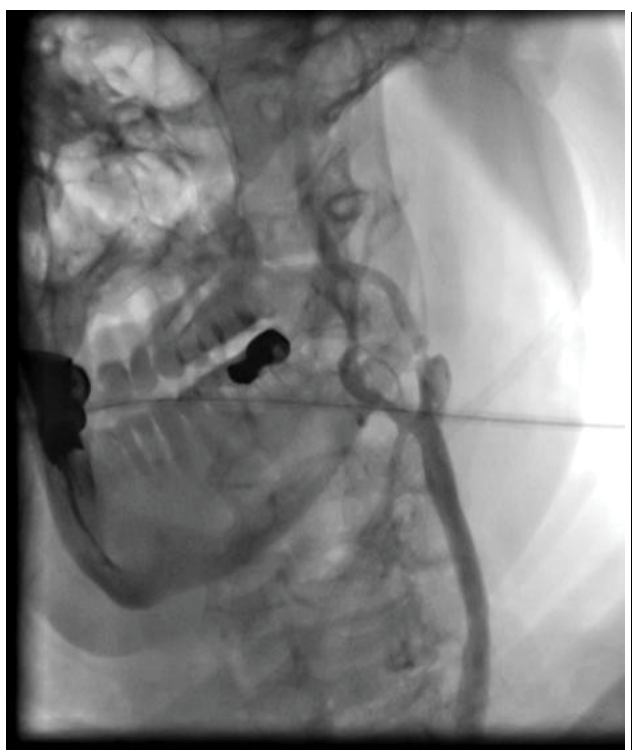

$\mathrm{D}$

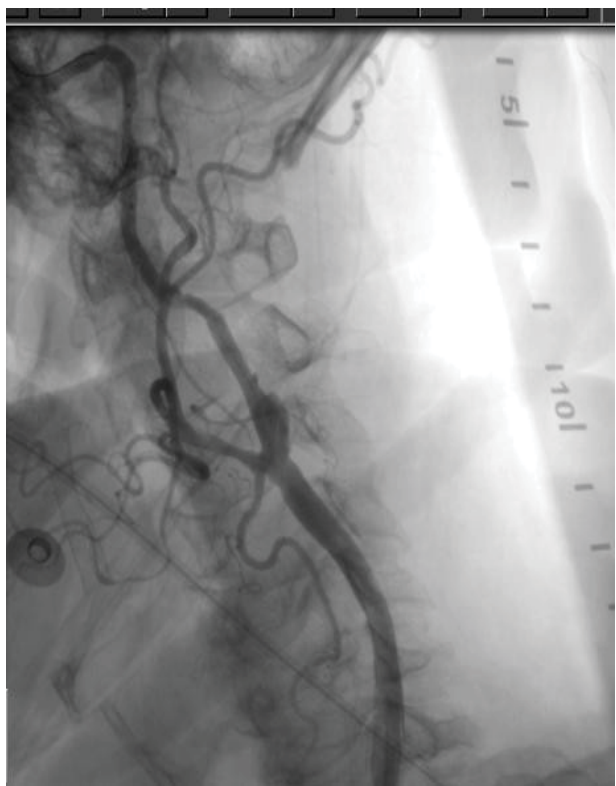

B

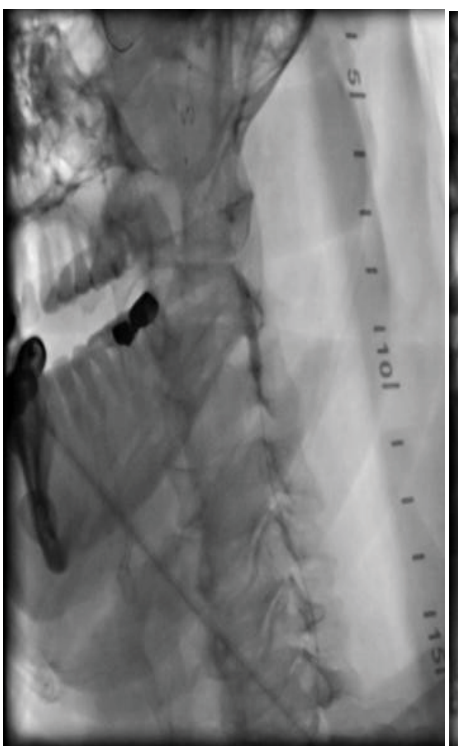

$\mathrm{E}$
$\mathrm{C}$

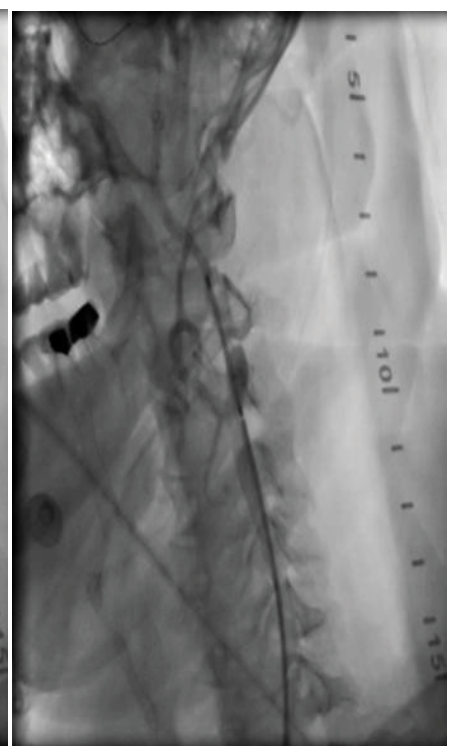

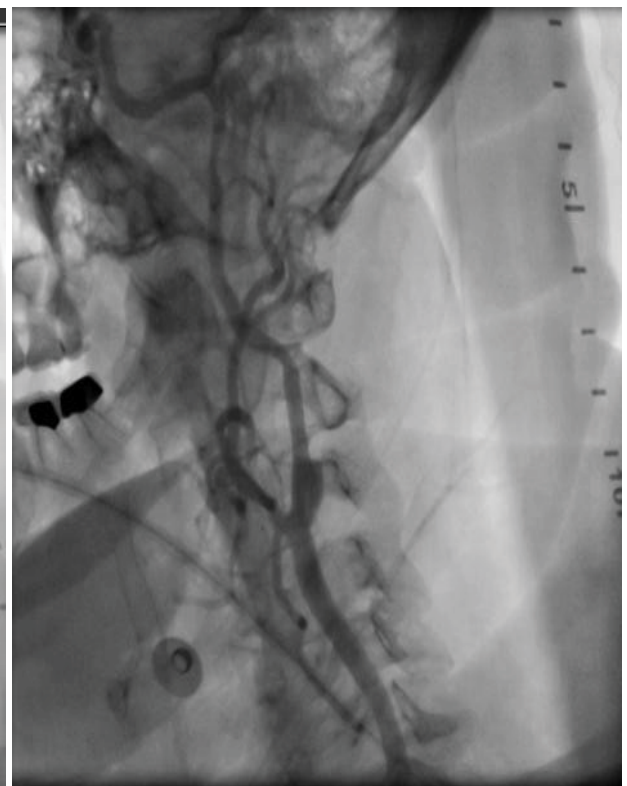

Figure 6: (A) Left internal carotid critical $99 \%$ stenosis (B) Angioplasty NAV 6 Emboshield distal filter (C) XACT stent $9 \times 7 \times 30$ $\mathrm{mm}$ ( $\mathrm{D}$ and $\mathrm{E})$ Post Stent.

educational and smoking cessation sessions. He was evaluated 3 months later for atypical chest pain and had nuclear stress test that was negative after 10 METS and showed normal myocardial perfusion.

\section{Discussion}

Our body circulation and vasculatures is just an interconnected tree i.e. a vascular pathology in one site, raise the probability of having other sites affected by about $50 \%$ within the vascular axis $[1,2]$. Hence once vascular pathology found in one site for example CAD, other sites i.e. Cerebral and peripheral circulation must be assessed thoroughly, especially in patients with multiple risk factors i.e. Hypertension, Diabetes, Dyslipidemia, Smoking, and positive family history for CAD. Assessment should view symptoms via a meticulous history, detailed examinations to exclude signs of ischemia, and thorough investigations. This will lead to accurate diagnosis and hence adequate management. 
A

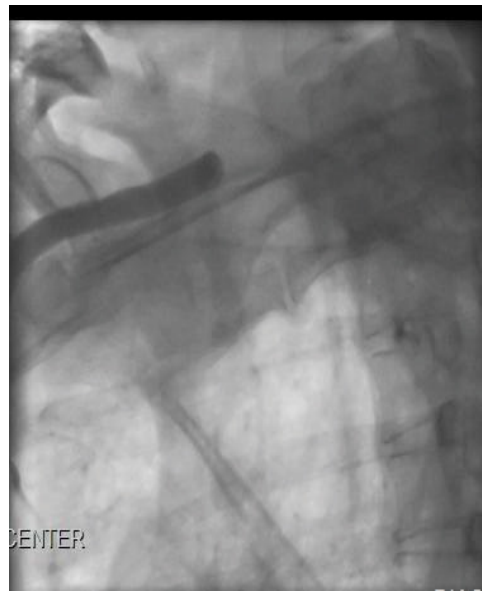

D
B
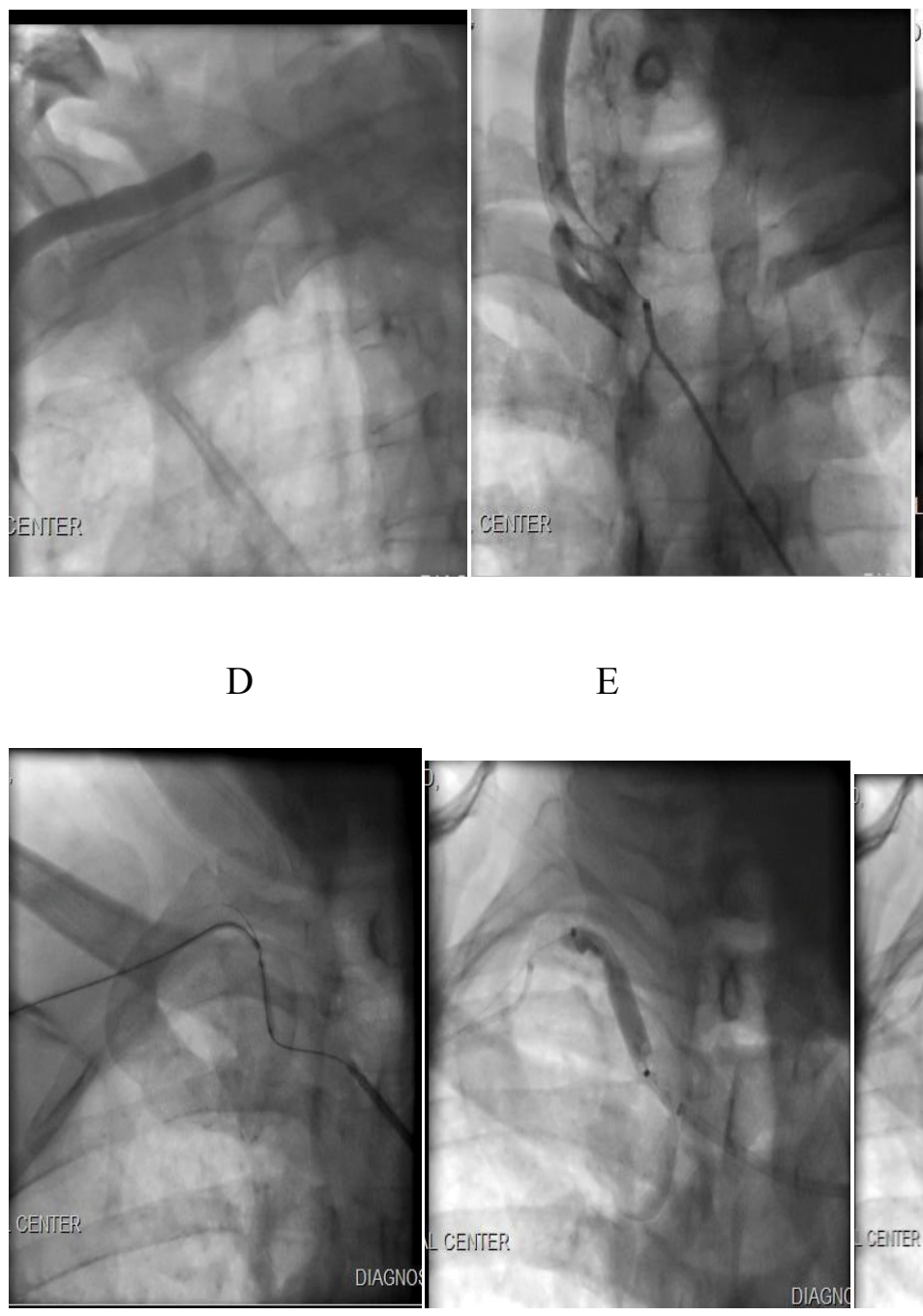

G
E

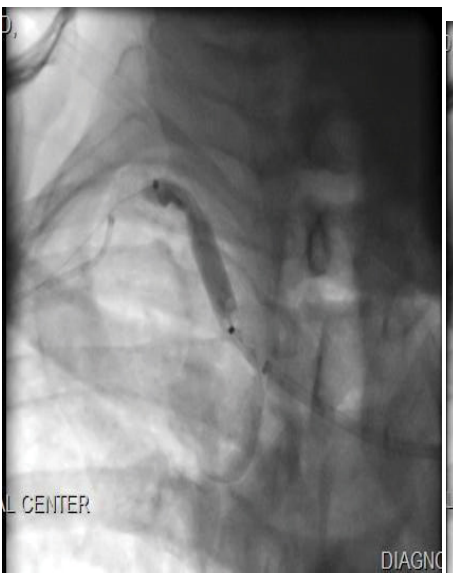

$\mathrm{H}$
C

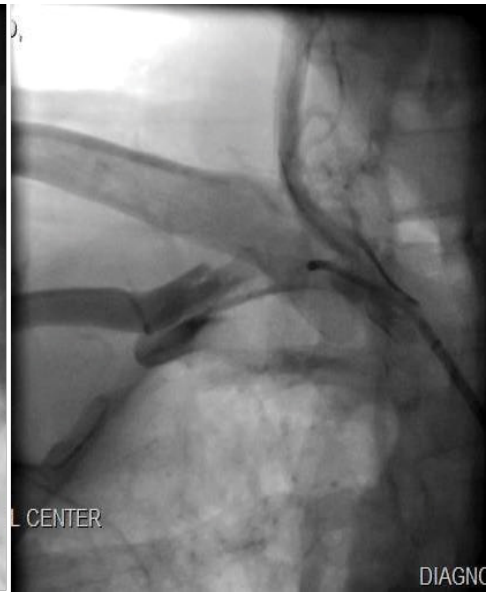

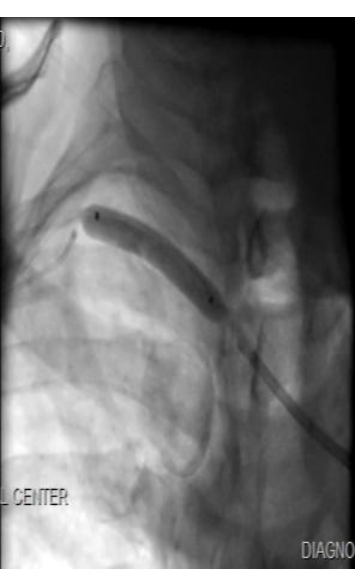

I

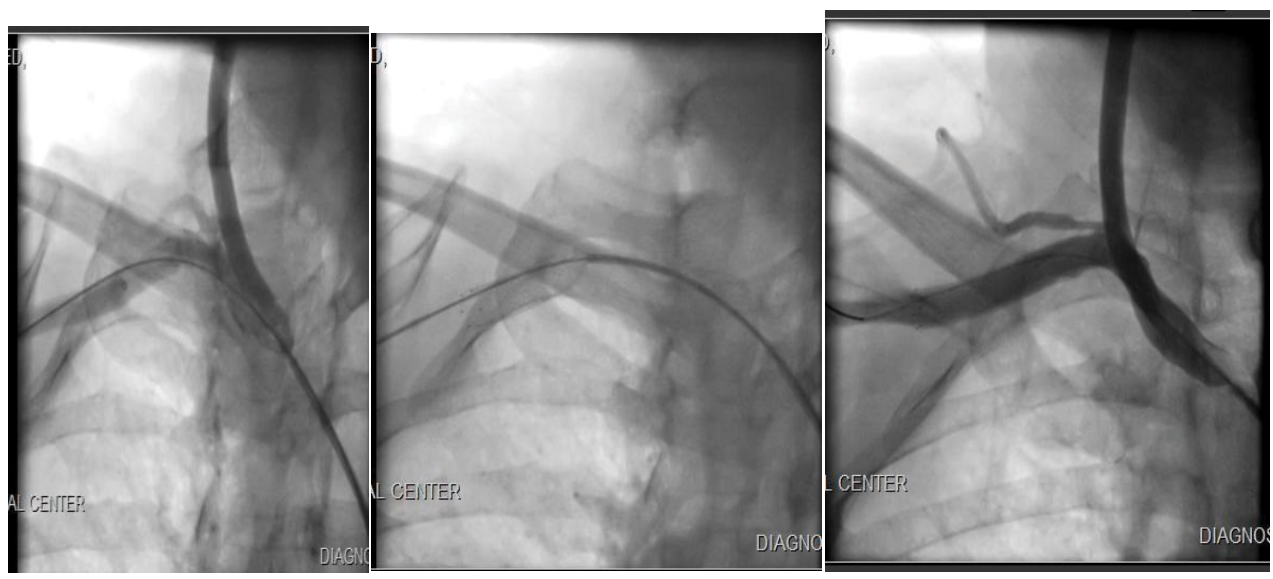

Figure 7: $(A$ and $B)$ Occluded right subclavian artery $(C)$ Antegrade and retrograde injection (D) Successful Wiring (E) Angioplasty (F) Angioplasty (G) Recanalization (H) (I) Post. 
A

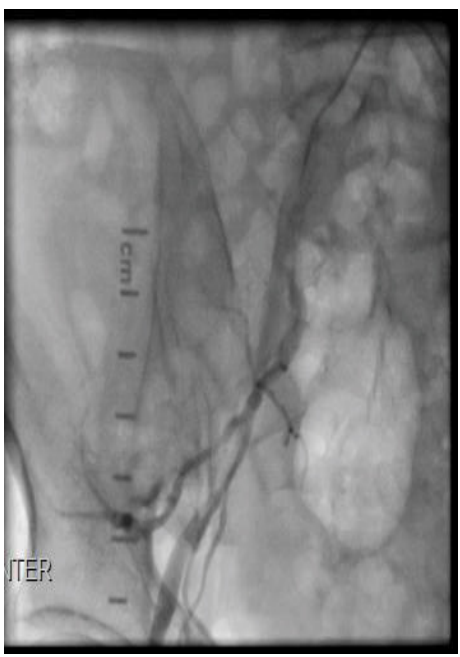

$\mathrm{D}$
$\mathrm{B}$

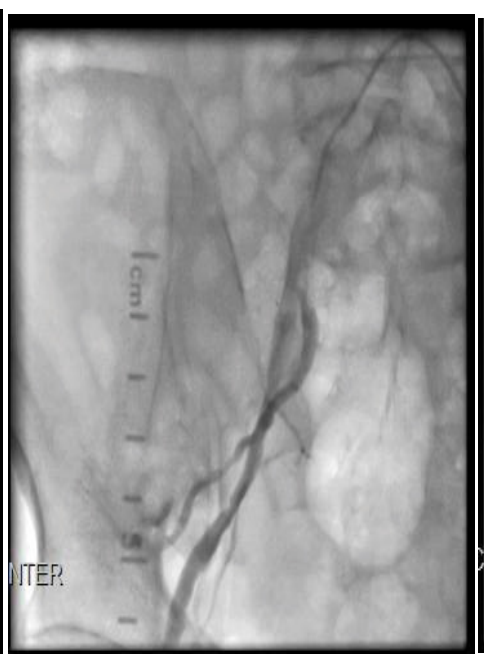

$\mathrm{E}$

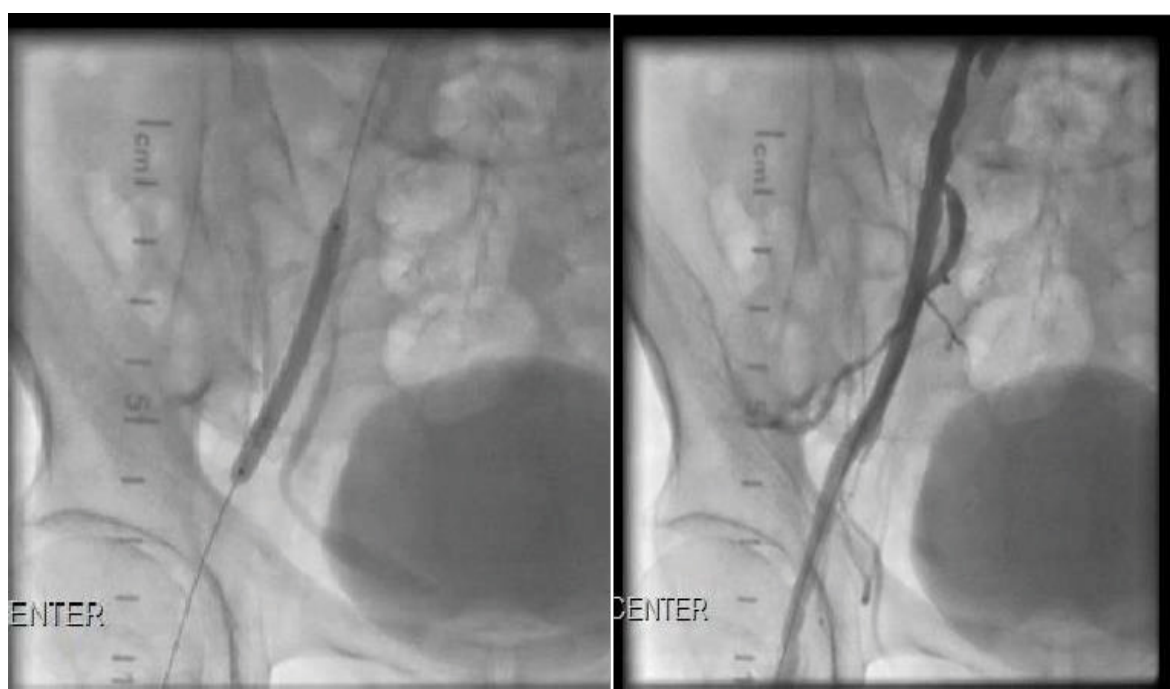

Figure 8: Right External Iliac angioplasty and stenting (A and B) Pre tight Ext lliac artery; (C) Angioplasty (D) Stenting $(7 \times 59 \mathrm{~mm}$ balloon expandable) (E) Post.

Coronary artery bypass graft (CABG) rather than PCI was the favored cost-effective treatment for complex multivessel coronary artery disease (MVCAD) in the long term. While the evidence base for the costeffectiveness of DES compared with CABG is growing [3]. Despite the benefits of Coronary Artery Bypass Graft surgery, $15 \%$ to $25 \%$ of patients develop graft closure within one year following the procedure [4].

Percutaneous intervention (PCI) is a conservative reasonable solution for high risk and inoperable cases; sometimes it supersedes the choice surgery especially with the new era of drug eluting stents (DES) and combined Anti-Ischemic medications. Stroke is a major cause of long-term disability and is the second leading cause of death in the world [5]. Carotid Stenosis especially symptomatic, bilateral, and high-grade stenosis, is an important independent risk factor for ischemic stroke [6-11]. Both sole medical treatment and vascular surgical interventions have been recommended for symptomatic Significant Carotid Stenosis [6-18].

Bilateral carotid severe stenosis can severely compromise the cerebral vasomotor reactivity and both hemispheric 
A
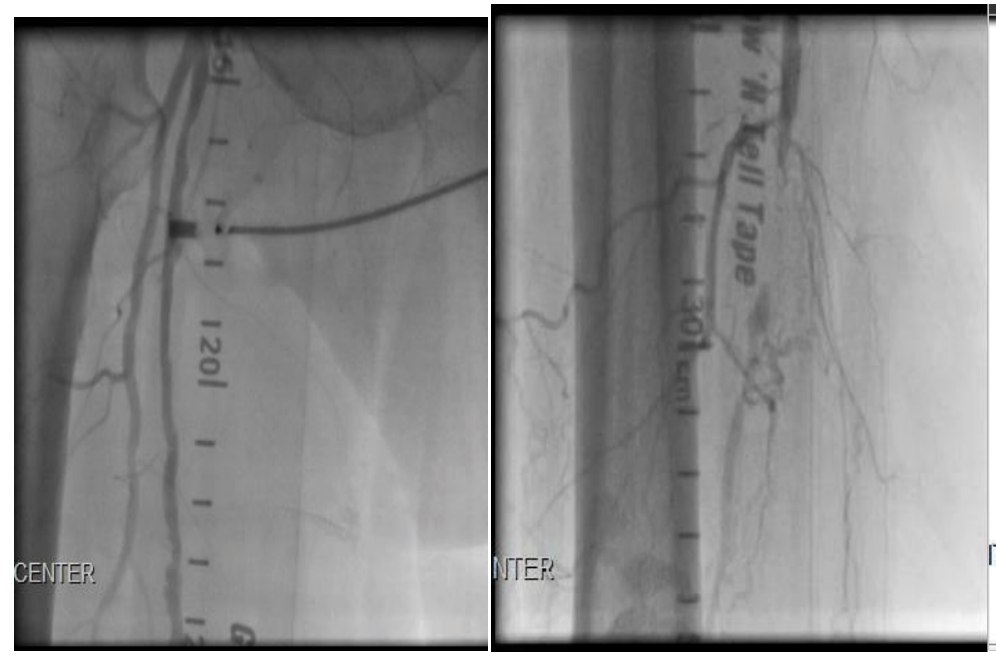

$\mathrm{D}$
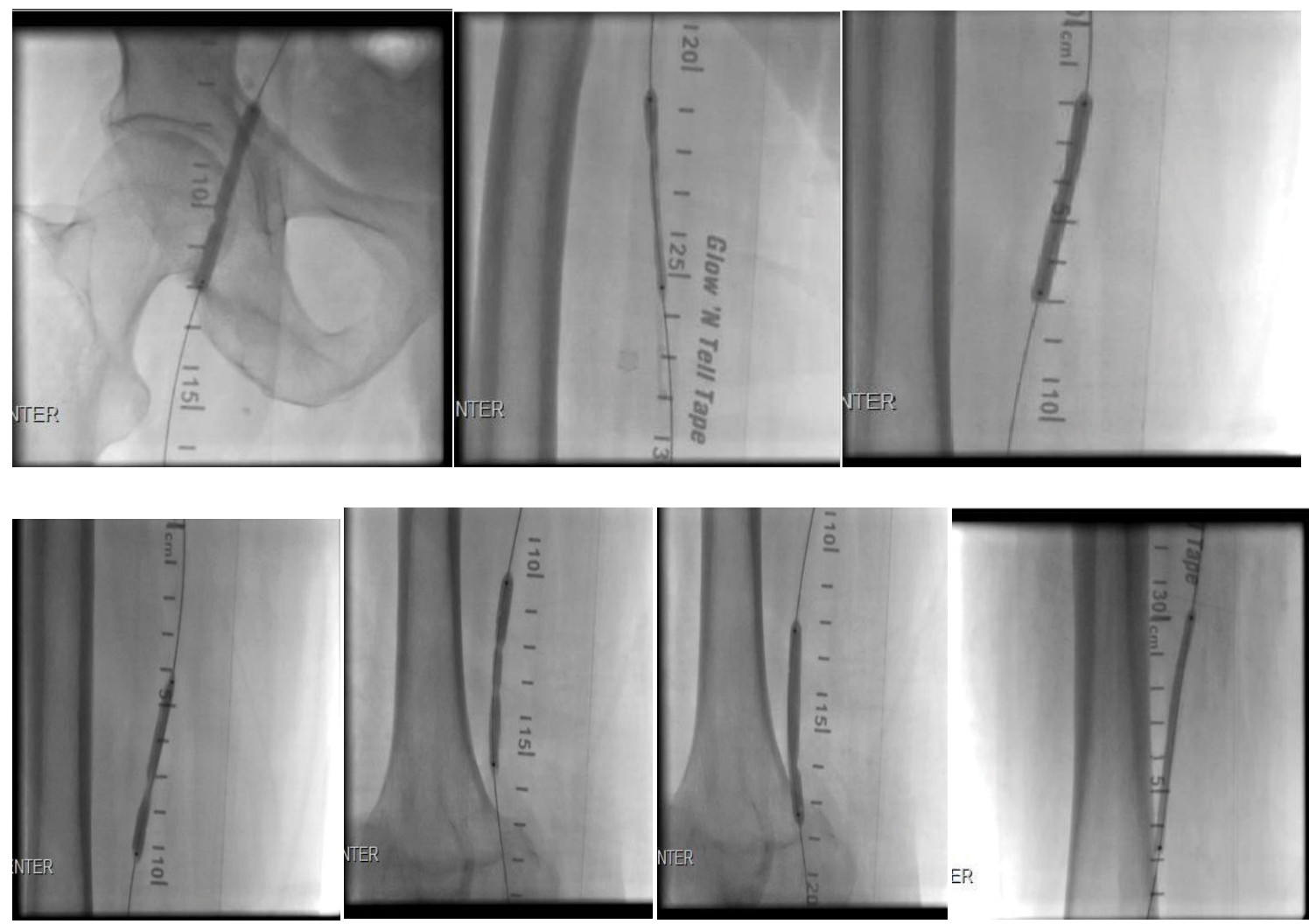

Figure 9: (A and B) Right SFA long diffuse and total occlusion (C) Occluded right TPT (D) Angioplasty along the right common femoral, superficial femoral and popliteal. 
A

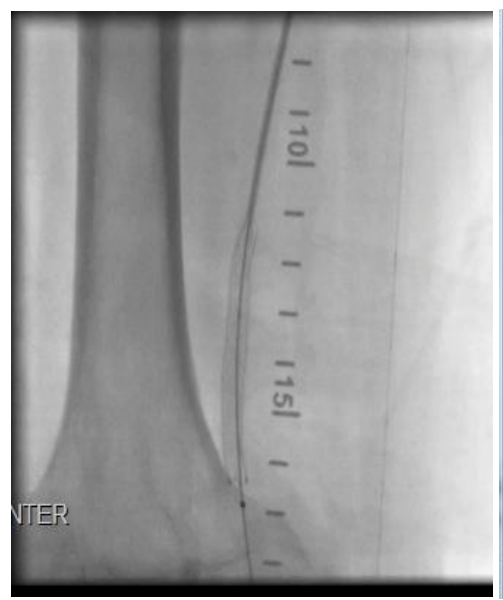

$\mathrm{B}$

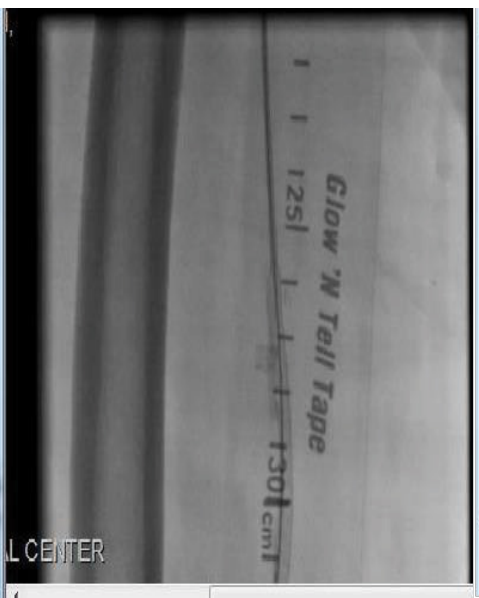

$\mathrm{C}$

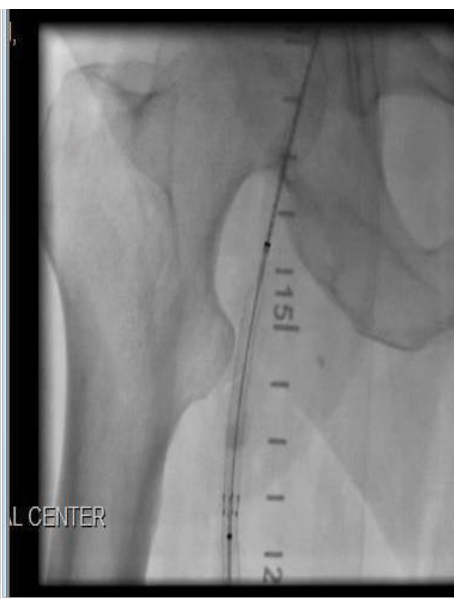

\section{Post Stenting}
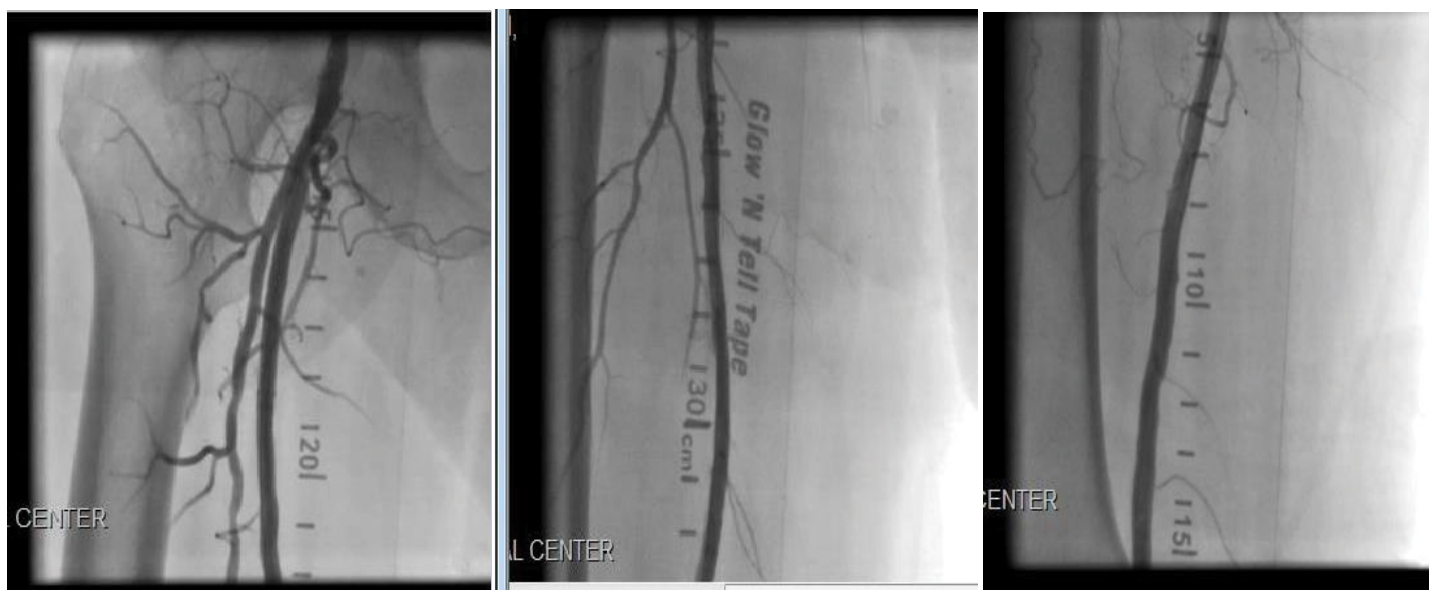

Figure 10: Right SFA 3 self expandable stents (A) Distal SFA (B) Mid SFA (C) Proximal SFA.

A

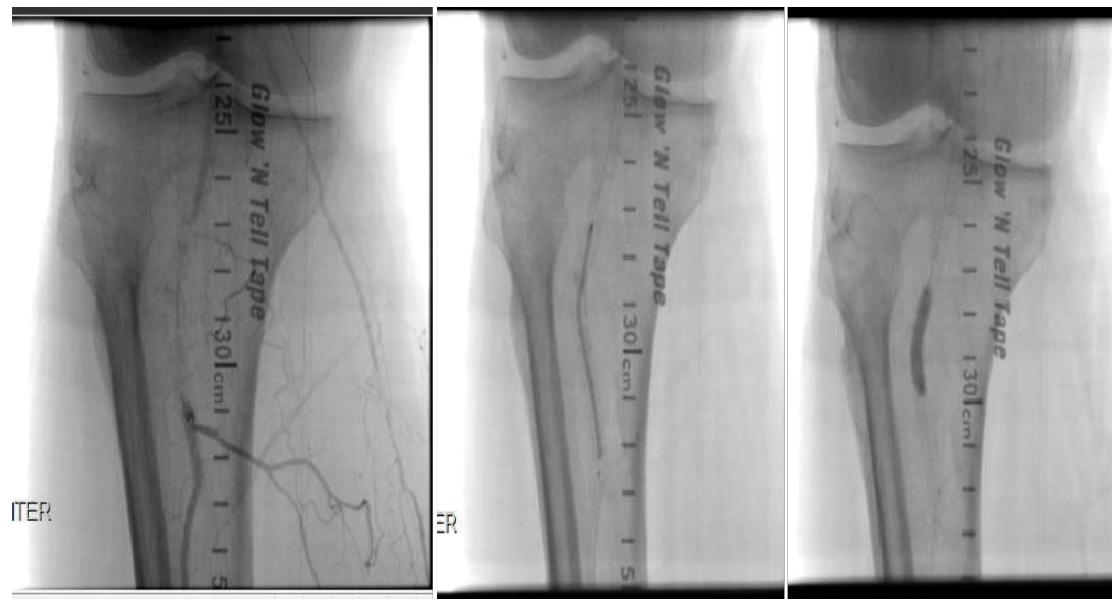

$\mathrm{B}$

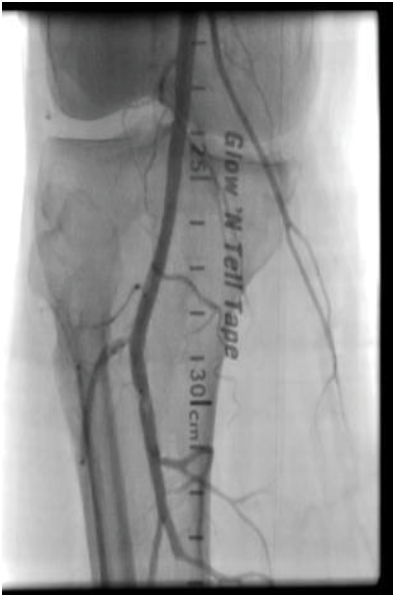

Figure 11: Occluded right TPT (A) Angioplasty/Stent (B) Post Stent. 
A

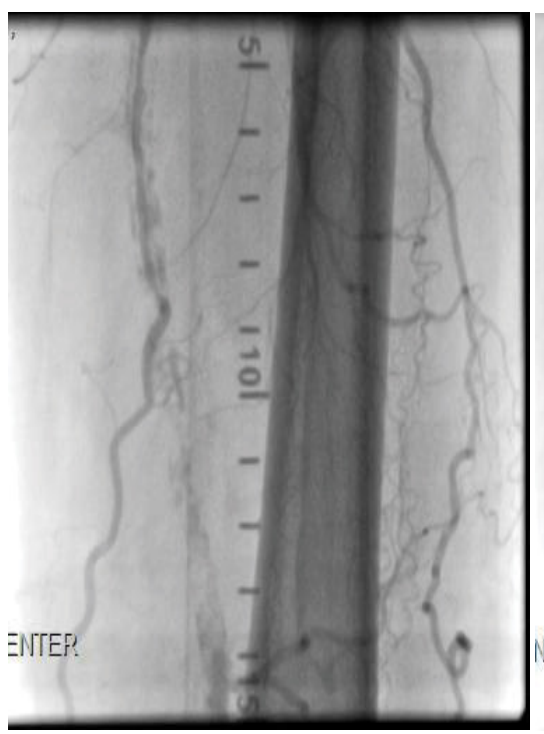

D
B

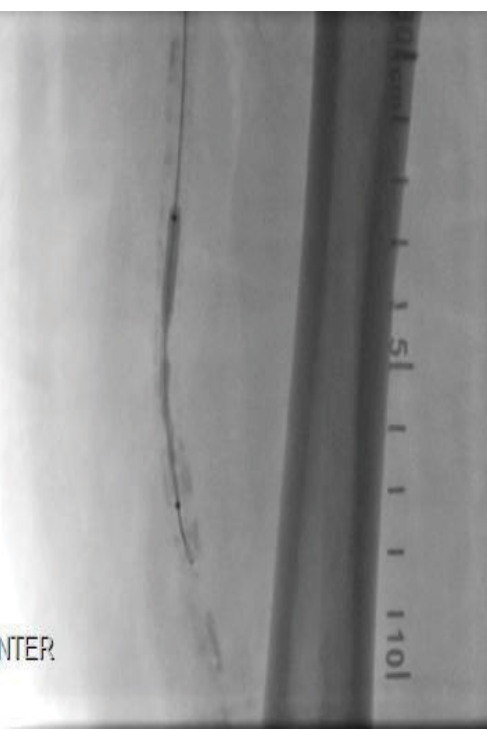

E
$\mathrm{C}$

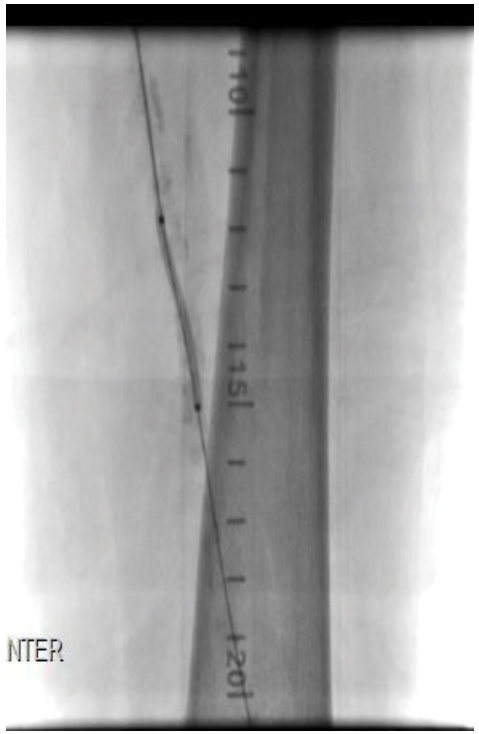

F

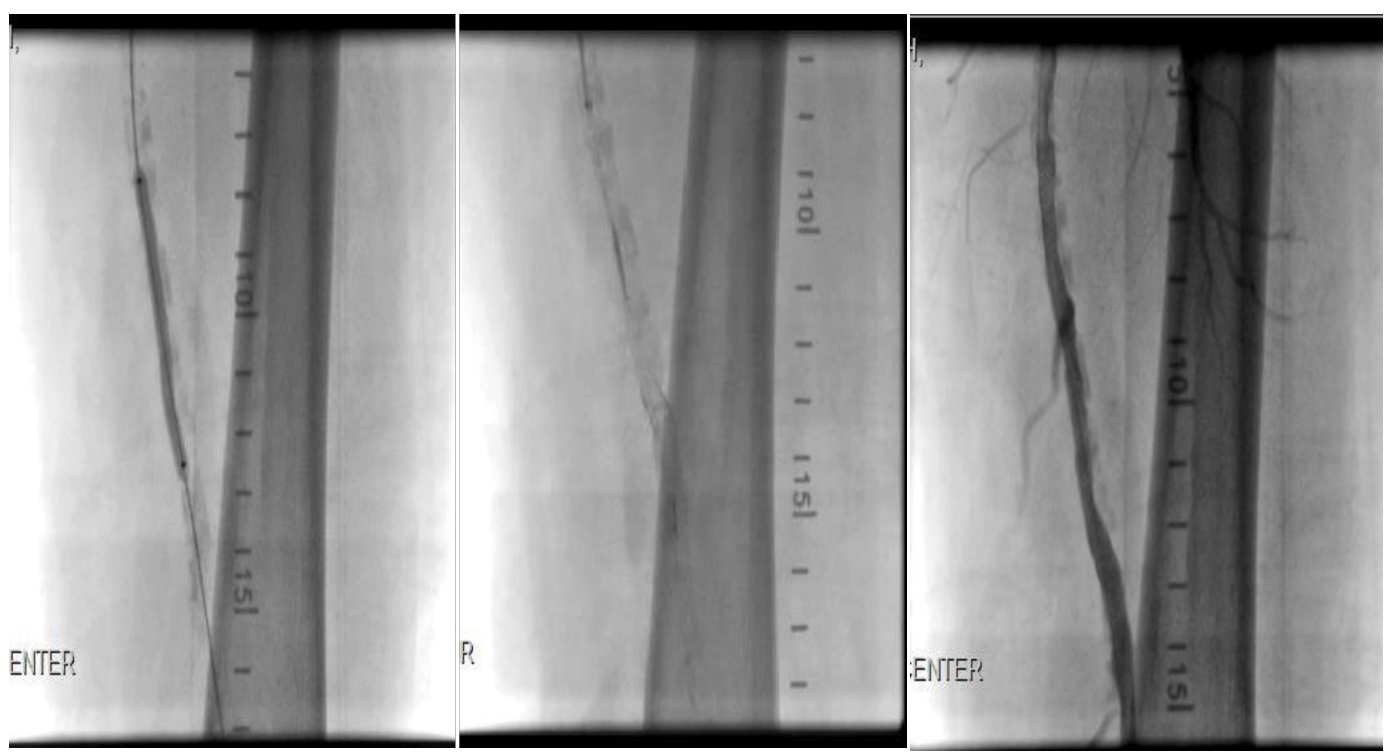

Figure 12: (A) Occluded left SFA (calcific) (B) Angioplasty (C) Angioplasty (D): Predilation (E) Supera Stent (F) Post Stent.

blood flow [19]. In spite of a controversial approach with regard to the optimal surgical intervention for symptomatic bilateral high-grade Carotid Stenosis [20], Carotid Artery Stenting (CAS) assisted by a distal protected device is more appropriate and advantageous than Carotid Endarterectomy [21-28], especially in a selected group of patients [29-32]. Furthermore, in spite of concerns about greater likelihood of hyperperfusion syndrome and hemodynamic depression, such as severe brain edema, bradycardia and hypotension, bilateral carotid stenting is still recommended and proven to be safe and effective for symptomatic bilateral high-grade Carotid Stenosis [23-28]. On the other hand, bilateral carotid stenting could also eliminate a wider range of additional medical, physical, and economic burdens imposed.

\section{Conclusion}

We here report a unique case of a patient with multiple atherosclerosis risk factors demonstrating multisite 
severe and critical stenosis and occlusion including CAD, Bilateral Carotid, Subclavian, Iliac, Femoral, and tibioperoneal trunk. He was deemed a very high risk for surgical intervention and underwent successful complex percutaneous transcatheter multivessel/multisite angioplasty and stents (total 16 stents) with excellent results and outcomes. To the best of our knowledge this case is among one of the very few reports if not the first report of multisite simultaneous and consecutive vascular intervention with $\mathrm{x}$ near total body stenting. 


\section{References}

1. Razzouk L, Caron B. Rockman CB, et al. Co-existence of vascular disease in different arterial beds: Peripheral artery disease and carotid artery stenosis. Atherosclerosis. 241(2): 68791 (2015).

2. Berger JS, Hochman J, Lobach I, et al. Modifiable risk factor burden and the prevalence of peripheral artery disease in different vascular territories. J Vasc Surg. 58: 673-81 (2013).

3. Ariyaratne TV, Yap C-h, Ademi Z, et al. A systematic review of cost-effectiveness of percutaneous coronary intervention vs. surgery for the treatment of multivessel coronary artery disease in the drug-eluting stent era. Eur Heart J. 2(4): 261-70 (2016).

4. Cicek D, Gokay S, Muderrisoglu H. Significant restenosis of multiple saphenous vein grafts early after coronary artery bypass graft surgery. J Med Cases. 2(5): 206-9 (2011).

5. Endarterectomy for asymptomatic carotid artery stenosis. Executive committee for the asymptomatic carotid atherosclerosis study. JAMA. 273: 1421-28 (1995).

6. Halliday A, Harrison M, Hayter E, et al. 10-Year stroke prevention after successful carotid endarterectomy for asymptomatic stenosis (ACST-1): a multicentre randomised trial. Lancet. 376: 1074-84 (1995).

7. Hobson RW II, Weiss DG, Fields WS, et al. Efficacy of carotid endarterectomy for asymptomatic carotid stenosis. N Engl J Med. 328: 221-27 (1993).

8. Barnett HJM, Taylor DW, et al. North American symptomatic carotid endarterectomy trial collaborators, beneficial effect of carotid endarterectomy in symptomatic patients with high-grade carotid stenosis. N Engl J Med. 325: 445 (1991).

9. MRC european carotid surgery trial: Interim results for symptomatic patients with severe $(70-99 \%)$ or with mild $(0$ 29\%) carotid stenosis. European Carotid Surgery Trialists' Collaborative Group. Lancet. 337: 1235 (1991).

10. Randomised trial of endarterectomy for recently symptomatic carotid stenosis: final results of the MRC European carotid surgery trial (ECST). Lancet. 351: 1379 (1998).

11. Paciaroni M, Eliasziw M, Sharpe BL, et al. Long-term clinical and angiographic outcomes in symptomatic patients with $70 \%$ to $99 \%$ carotid artery stenosis. Stroke. 31: 2037 (2000).

12. He J, Zhang Y, Xu T, et al. Effects of immediate blood pressure reduction on death and major disability in patients with acute ischemic stroke: The CATIS randomized clinical trial. JAMA. 311(5): 479-89 (2014)

13. den Hartog AG, Achterberg S, Moll FL, et al. Asymptomatic carotid artery stenosis and the risk of ischemic stroke according to subtype in patients with clinical manifest arterial disease. Stroke 44(4): 1002-7 (2013).

14. King A, Shipley M, Markus H, et al. The effect of medical treatments on stroke risk in asymptomatic carotid stenosis. Stroke. 44(2): 542-46 (2013)

15. Marnane M, Prendeville S, McDonnell C, et al. Plaque inflammation and unstable morphology are associated with early stroke recurrence in symptomatic carotid stenosis. Stroke. 45(3): 801-6 (2014).

16. Johansson E, Wester P. Recurrent stroke risk is high after a single cerebrovascular event in patients with symptomatic 50-99\% carotid stenosis: a cohort study. BMC Neurol. 14: 23 (2014).

17. Moustafa RR, Izquierdo-Garcia D, Jones PS, et al. Watershed infarcts in transient ischemic attack/minor stroke with $>$ or $=50 \%$ carotid stenosis: hemodynamic or embolic? Stroke. 41(7): 141016 (2010).

18. Ederle J, Brown MM. The evidence for medicine versus surgery for carotid stenosis. Eur J Radiol. 60(1): 3-7 (2006).

19. Gur AY, Bornstein NM. Cerebral vasomotor reactivity of bilateral severe carotid stenosis: is stroke unavoidable? Eur J Neurol. 13(2): 183-86 (2006).

20. Farsak B, Oc M, Boke E. Simultaneous bilateral carotid endarterectomy: our first experience. Ann Thorac Cardiovasc Surg. 7(5): 292-96 (2001).

21. Yan Y, Yuan Y, Liang L, et al. Influence of carotid artery stenting on cognition of elderly patients with severe stenosis of the internal carotid artery. Med Sci Monit. 20: 1461-68 (2014).

22. Sakai N, Yamagami H, Matsubara Y, et al. Prospective registry of carotid artery stenting in Japan-investigation on device and antiplatelet for carotid artery stenting. J Stroke Cerebrovasc Dis. 23(6): 1374-84 (2014).

23. Naggara O, Touze E, Beyssen B, et al. Anatomical and technical factors associated with stroke or death during carotid angioplasty and stenting: results from the endarterectomy versus angioplasty in patients with symptomatic severe carotid stenosis (EVA-3S) trial and systematic review. Stroke. 42(2): 380-88 (2011).

24. Henry M, Gopalakrishnan L, Rajagopal S, et al. Bilateral carotid angioplasty and stenting. Catheter Cardiovasc Interv. 64(3): 27582 (2005).

25. Dong H, Jiang XJ, Peng M, et al. Comparison of the safety of simultaneous bilateral carotid artery stenting versus unilateral carotid artery stenting: 30-day and 6-month results. Chin Med J. 125(6): 1010-15 (2012).

26. Halse O, Clifton A, Cloud GC. Endovascular intervention for symptomatic bilateral carotid artery stenosis in an octogenarian. Age Ageing. 36(1): 102-4 (2007).

27. Chen MS, Bhatt DL, Mukherjee D, et al. Feasibility of simultaneous bilateral carotid artery stenting. Catheter Cardiovasc Interv. 61(4): 437-42 (2004).

28. Li Y, Sun W, Yin Q, et al. Safety and efficacy of simultaneous bilateral carotid angioplasty and stenting. J Thromb Thrombolysis. 37(2): 202-9 (2014).

29. Lesley WS, Lazo A, Kazmierczak CD, Wilseck JM. Simultaneous bilateral carotid stenting for postendarterectomy restenosis. Catheter Cardiovasc Interv. 58(2): 147-50 (2003).

30. Lee YH, Kim TK, Suh SI, et al. Simultaneous bilateral carotid stenting under the circumstance of neuroprotection device. A retrospective analysis. Interv Neuroradiol. 12(2): 141-48 (2006).

31. Massop D, Dave R, Metzger C, et al. Stenting and angioplasty with protection in patients at high-risk for endarterectomy: SAPPHIRE Worldwide Registry first 2,001 patients. Catheter Cardiovasc Interv. 73(2): 129-36 (2009).

32. Liu S, Jung JH, Kim SM, et al. Simultaneous bilateral carotid stenting in high-risk patients. Am J Neuroradiol. 31(6): 1113-17 (2010). 